\title{
Chebyshev approximation of the steel magnetization characteristic by the sum of a linear expression and an arctangent function
}

\author{
Malachivskyy P. ${ }^{1,2}$, Pizyur Ya. ${ }^{3}$ \\ ${ }^{1}$ Centre of Mathematical Modelling of Ukrainian National Academy of Sciences, \\ 15 Dudayev Str., 79005, Lviv, Ukraine \\ ${ }^{2}$ Ukrainian Academy of Printing, \\ 19 Pid Holoskom Str., 79020, Lviv, Ukraine \\ ${ }^{3}$ Lviv Polytechnic National University, \\ 12 S. Bandera Str., 79013, Lviv, Ukraine
}

(Received 6 March 2019; Accepted 8 April 2019)

\begin{abstract}
The properties of a Chebyshev approximation by the sum of a linear expression and an arctangent function have been investigated. The condition has been established under which a Chebyshev approximation by this expression with the smallest absolute error and with the reproduction of the function value at the leftmost point exists and is unique. A method of determining the parameters of this approximation has been suggested and substantiated. The results of a Chebyshev approximation of the magnetization characteristic of electrotechnical steel by the sum of a linear expression and an arctangent function have been presented.
\end{abstract}

Keywords: Chebyshev (uniform) approximation with condition, Chebyshev alternance points, magnetization characteristic of steel.

2000 MSC: $41 \mathrm{~A} 50,41 \mathrm{~A} 52$

UDC: 519.65

DOI: $10.23939 / \mathrm{mmc} 2019.01 .077$

\section{Introduction}

Approximation by the sum of a linear expression and an arctangent function is used in the modeling of ferroresonance processes according to the main magnetization curve [1]. For simulation of nonlinear inductive elements, the main magnetization curve, which passes through the vertices of hysteresis cycles, obtained during the cyclic remagnetization of the core, is most often used. This curve geometrically depicts the dependence of magnetic induction on the intensity of the magnetic field $B=f(H)[1,2]$. In the works [1,3], the satisfactory accuracy of the approximation of the magnetization curve of nonlinear inductive elements is achieved using the sum of the linear expression and the arctangent function with three coefficients

$$
B(H)=b H+c \arctan (d H),
$$

where $B$ is magnetic induction, $H$ is the magnetic field strength, and $b, c, d$ are coefficients of approximation. In accordance with the results of [1,2], the model (1) provides a satisfactory approximation on all characteristic sections of the magnetization curve and involves a reproduction of the nature of the development of ferroresonance process taking into account the initial conditions. However, there is no effective method for determining the approximation (1) on the basis of experimental data [4]. For example, in [5], the coefficients of the approximation (1) for the experimental data are calculated as interpolation for the chosen three points, and to improve this approximation, they suggest adjusting it.

In this paper, for the approximation of a magnetization curve of nonlinear inductive elements, we suggest the use of a Chebyshev approximation by the sum of a linear expression and an arctangent function [6]. The choice of a Chebyshev approximation is due to the fact that it ensures the achievement of the least possible error of approximation on a given interval [7]. The quality of approximation 
of the characteristics of steel magnetization is of great importance in solving the problems of the analysis of processes in electrical engineering devices with ferromagnetic elements since very often not only quantitative but also qualitative results of solving the corresponding problems depend on methods of representing these curves [4]. Using the approximation of a magnetization characteristic by a single analytical expression on the entire interval [4], in some cases gives an opportunity to obtain an analytical solution to the problem analyzing processes in electrical engineering devices with ferromagnetic elements.

A Chebyshev approximation by the expression (1) is a partial case of the Chebyshov approximation of the sum of a linear expression and an arctangent function

$$
B_{1}(x)=a+b x+c \arctan (d x), \quad x \geqslant 0, \quad d>0
$$

concerning the unknown parameters $a, b, c$ and $d$. According to [8], a Chebyshev approximation by the expression (1) is a Chebyshev approximation by the expression (2) with the condition of reproduction at the point $x=0$ of the zero value of the approximate function. The expression (2) does not satisfy the Haar's condition $[9,10]$, and therefore the question arises about the existence and uniqueness of a Chebyshev approximation by such an expression. In this connection, it is necessary to investigate the properties of a Chebyshev approximation by the expression (2) and to define a class of functions for which such a Chebysh approximation exists. In this paper, the existence of a Chebyshev approximation by the expression (2) with reproduction of the values of the function at the leftmost point is investigated and a method for determining the parameters of such an approximation is suggested.

\section{Existence of a Chebyshev approximation by the sum of a linear expression and an arctangent function}

We investigate the existence of a Chebyshev approximation by the sum of a linear expression and an arctangent function (2). The class of functions $f(x)$ for which a Chebyshev approximation by the expression (2) with the smallest absolute error on the interval $[\alpha, \beta]$ and with the reproduction of the value of the function at the leftmost point of the interval exists, is defined by the theorem.

Theorem 1. A sufficient condition for the existence of a Chebyshev approximation by the expression (2) for the continuous function $f(x)$ with the smallest absolute error on the interval $[\alpha, \beta], \alpha \geqslant 0$, and with the reproduction of the value of the function at the point $\alpha$ is the implementation of inequalities

where

$$
0<\widetilde{W}<W<W_{0}
$$

$$
\begin{aligned}
& W=\frac{\frac{f\left(z_{4}\right)-f\left(z_{2}\right)}{z_{4}-z_{2}}-\frac{f\left(z_{3}\right)-f\left(z_{1}\right)}{z_{3}-z_{1}}}{\frac{f\left(z_{3}\right)-f\left(z_{1}\right)}{z_{3}-z_{1}}-\frac{f\left(z_{2}\right)+f\left(z_{1}\right)-2 f(\alpha)}{z_{2}+z_{1}-2 \alpha}}, \\
& W_{0}=\frac{z_{2}^{2}+z_{2} z_{4}+z_{4}^{2}-z_{1}^{2}-z_{1} z_{3}-z_{3}^{2}}{z_{1}^{2}+z_{1} z_{3}+z_{3}^{2}-\frac{z_{1}^{3}+z_{2}^{3}-2 \alpha^{3}}{z_{1}+z_{2}-2 \alpha}} \\
& \widetilde{W}=\frac{\alpha z_{2}^{2} z_{4}+\alpha z_{1} z_{2} z_{4}-2 \alpha^{2} z_{2} z_{4}-\alpha z_{1} z_{2} z_{3}-\alpha z_{1}^{2} z_{3}+2 \alpha^{2} z_{1} z_{3}}{2 z_{1} z_{2} z_{3} z_{4}-\alpha z_{1} z_{2} z_{4}-\alpha z_{1} z_{3} z_{4}+2 \alpha^{2} z_{2} z_{4}-\alpha z_{2}^{2} z_{4}-\alpha z_{2} z_{3} z_{4}},
\end{aligned}
$$

and $z_{i}(i=\overline{1,4})$ are any positive numbers from $(\alpha, \beta]$ arranged in ascending order.

Proof. According to the characteristic property [11], for the existence of a Chebyshev approximation by the sum of a linear expression and an arctangent function (2) of the function $f(x)$ with the smallest absolute error on the interval $[\alpha, \beta]$ and with the reproduction of the value of $f(x)$ at the leftmost 
point of this interval, it is sufficient that the system of equations

$$
\left\{\begin{array}{l}
f(\alpha)-a-b \alpha-c \arctan (d \alpha)=0 \\
f\left(z_{j}\right)-a-b z_{j}-c \arctan \left(d z_{j}\right)=(-1)^{j} \mu, \quad j=\overline{1,4}
\end{array}\right.
$$

has a unique solution in terms of the unknown parameters $a, b, c, d$ and the error $\mu$, where $z_{i}(i=\overline{1,4})$ are any numbers from $(\alpha, \beta]$ arranged in ascending order. We show that if the condition (3) is satisfied, the system of equations (7) has a unique solution.

By excluding from the system of equations (7) the unknown values $a$ and $\mu$, we obtain the system of equations in terms of $b, c$ and $d$

$$
\left\{\begin{array}{l}
b\left(z_{2}+z_{1}-2 \alpha\right)-c\left(\arctan \left(d z_{2}\right)+\arctan \left(d z_{1}\right)-2 \arctan (d \alpha)\right)=f\left(z_{2}\right)+f\left(z_{1}\right)-2 f(\alpha) \\
b\left(z_{3}-z_{1}\right)-c\left(\arctan \left(d z_{3}\right)-\arctan \left(d z_{1}\right)\right)=f\left(z_{3}\right)-f\left(z_{1}\right) \\
b\left(z_{4}-z_{2}\right)-c\left(\arctan \left(d z_{4}\right)-\arctan \left(d z_{2}\right)\right)=f\left(z_{4}\right)-f\left(z_{2}\right)
\end{array}\right.
$$

Since $z_{i}(i=\overline{1,4})$ are positive numbers from $(\alpha, \beta]$ arranged in ascending order, $0 \leqslant \alpha<z_{1}$, then from the system (8) it is possible to exclude the unknown $b$. Consequently, with respect to $c$ and $d$, we obtain a system of equations

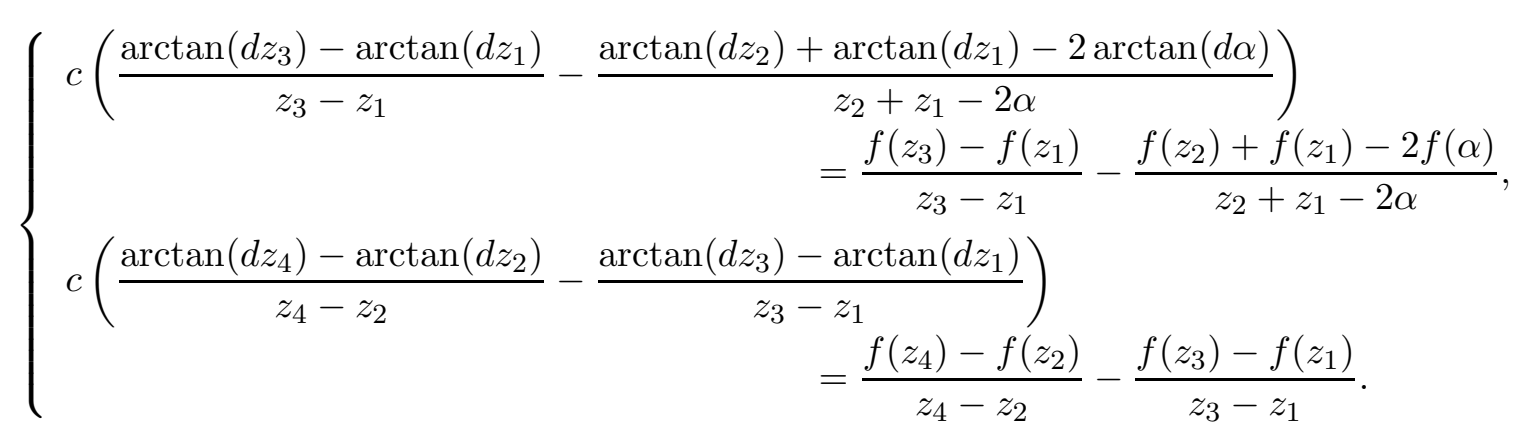

Consider the coefficients of the unknown $c$. In accordance with the Lagrange theorem on the finite increments of a continuously differentiable function [12], we obtain that the relationship

$$
\frac{\arctan \left(d z_{j+2}\right)-\arctan \left(d z_{j}\right)}{z_{j+2}-z_{j}}, \quad j=1,2
$$

is equal to the derivative of the arctangent function $\arctan ^{\prime}\left(\xi_{j}\right)$ at some midpoints of the corresponding intervals $\xi_{j} \in\left[z_{j}, z_{j+2}\right], j=1,2$ i.e.

$$
\frac{\arctan \left(d z_{j+2}\right)-\arctan \left(d z_{j}\right)}{z_{j+2}-z_{j}}=\frac{d}{1+d^{2} \xi_{j}^{2}}, \quad \xi_{j} \in\left[z_{j}, z_{j+2}\right], \quad j=1,2 .
$$

In accordance with the theorem on the combination of increments of a continuously differentiable function [8]

$$
\frac{\arctan \left(d z_{2}\right)+\arctan \left(d z_{1}\right)-2 \arctan (d \alpha)}{z_{2}+z_{1}-2 \alpha}=\frac{d}{1+d^{2} \xi_{0}^{2}}, \quad \xi_{0} \in\left[\alpha, z_{2}\right] .
$$

Consequently, since the points $z_{i}(i=\overline{1,4})$ are arranged in ascending order and $0 \leqslant \alpha<z_{1}$, then the coefficients of the unknown $c$ in the system of equations (9) acquire only positive values. Therefore, we obtain a transcendental equation of $d$

$$
G(d)=W
$$

where

$$
G(d)=\frac{\frac{\arctan \left(d z_{4}\right)-\arctan \left(d z_{2}\right)}{z_{4}-z_{2}}-\frac{\arctan \left(d z_{3}\right)-\arctan \left(d z_{1}\right)}{z_{3}-z_{1}}}{\frac{\arctan \left(d z_{3}\right)-\arctan \left(d z_{1}\right)}{z_{3}-z_{1}}-\frac{\arctan \left(d z_{2}\right)+\arctan \left(d z_{1}\right)-2 \arctan (d \alpha)}{z_{2}+z_{1}-2 \alpha}},
$$


and the value $W$ is determined by the formula (4). Taking into account the relationships (10) and (11) and applying to $G(d)$ the Lagrange's mean value theorem [12] on the finite increment of a continuously differentiable function, we obtain

$$
G(d)=\frac{\left(\xi_{1}-\xi_{0}\right)\left(1+d^{2} \zeta_{1}^{2}\right)^{2} \zeta_{2}}{\left(\xi_{2}-\xi_{1}\right)\left(1+d^{2} \zeta_{2}^{2}\right)^{2} \zeta_{1}}, \quad \zeta_{j} \in\left[\xi_{j}, \xi_{j+1}\right], \quad j=1,2 .
$$

Consequently, the function $G(d)$, the left side of the equation (12), for positive and arranged in ascending order points $z_{i}(i=\overline{1,4})$ is a strictly monotonically decreasing function for $d \in(0, \infty)$ and acquires only positive values. Since

$$
\lim _{d \rightarrow 0} G(d)=W_{0} \quad \text { and } \quad \lim _{d \rightarrow \infty} G(d)=\widetilde{W}
$$

then for $d \in(0, \infty)$, the left side of the equation (12) acquires values from the interval $\left(\widetilde{W}, W_{0}\right)$. Therefore, in the case when the condition (3) holds, the equation (12)) and, accordingly, the system of equations (7) has a single real solution. The convergence of the iterative Remez algorithm [7] indicates the existence of a Chebyshev approximation for the continuous functions $f(x)$ by the expression (2) on the interval $[\alpha, \beta]$ for $\alpha \geqslant 0$ in the case when the condition (3) holds.

Consequently, for the continuous functions $f(x)$ satisfying the condition (3), a Chebyshev approximation by the expression (2) with the smallest absolute error on the interval $[\alpha, \beta]$ and with the reproduction of the value of the function at the point $\alpha$ exists. The theorem is proved.

Let us investigate the sufficient condition (3) of the existence of a Chebyshev approximation by the expression (2). According to the Lagrange's theorem [12] on the finite increments of a continuously differentiable function and taking into account the theorem on the combination of increments of a continuously differentiated function [8], the values of $W(4)$ can be presented as follows

$$
W=\frac{f^{\prime}\left(\xi_{2}\right)-f^{\prime}\left(\xi_{1}\right)}{f^{\prime}\left(\xi_{1}\right)-f^{\prime}\left(\xi_{0}\right)}
$$

where $\xi_{j} \in\left[z_{j}, z_{j+2}\right], j=1,2$, and $\xi_{0} \in\left[\alpha, z_{2}\right]$. From (15) we have that the variable $W$ will acquire positive values on the interval $[\alpha, \beta]$ if the function $f(x)$ and its derivative are strictly monotone on $[\alpha, \beta]$.

For strictly monotone functions, the derivative of which is also strictly monotone, the right inequality of the condition (3) can be presented as follows

$$
\frac{\frac{f\left(z_{4}\right)-f\left(z_{2}\right)}{z_{4}-z_{2}}-\frac{f\left(z_{3}\right)-f\left(z_{1}\right)}{z_{3}-z_{1}}}{\frac{z_{4}^{3}-z_{2}^{3}}{z_{4}-z_{2}}-\frac{z_{3}^{3}-z_{1}^{3}}{z_{3}-z_{1}}}<\frac{\frac{f\left(z_{3}\right)-f\left(z_{1}\right)}{z_{3}-z_{1}}-\frac{f\left(z_{2}\right)+f\left(z_{1}\right)-2 f(\alpha)}{z_{2}+z_{1}-2 \alpha}}{\frac{z_{3}^{3}-z_{1}^{3}}{z_{3}-z_{1}}-\frac{z_{2}^{3}+z_{1}^{3}-2 \alpha^{3}}{z_{2}+z_{1}-2 \alpha}} .
$$

Having applied to each of the parts of this inequality the theorems of Cauchy and Lagrange on the finite increments of continuously differentiable functions [12], taking into account the theorem on the combination of increments of a continuously differentiated function [8], we obtain

$$
\frac{f^{\prime \prime}\left(\zeta_{2}\right)}{\zeta_{2}}<\frac{f^{\prime \prime}\left(\zeta_{1}\right)}{\zeta_{1}}
$$

where $\zeta_{2} \in\left[z_{1}, z_{4}\right]$, and $\zeta_{1} \in\left[\alpha, z_{3}\right]$. From (17) we have that the second derivative of the function $f(x)$ must be also a strictly monotone function, moreover, the rate of change of its values should not exceed the rate of change of the linear function.

Consequently, the sufficient condition (3) for the existence of a Chebyshev approximation by the expression (2) with the smallest absolute error on the interval $[\alpha, \beta]$ and with the reproduction of the 
function at the point $\alpha$ satisfies, in particular, the continuously differentiable functions $f(x)$ if the function and its two derivatives are strictly monotone on $[\alpha, \beta]$. Moreover, the rate of change of the values of the second derivative should not exceed the rate of change of the linear function.

It is worth noting that the condition (3) is not necessary for the existence of a Chebyshev approximation of the function $f(x)$ by the expression (2) with the absolute error on the interval $[\alpha, \beta]$ and with the reproduction of the value of the function at the point $\alpha$. Its satisfaction is necessary only at the points of a Chebyshev alternance. In the case of the use of the Remez algorithm for finding the parameters of a Chebyshev approximation by the expression (2), the condition (3) must be satisfied at all points of the intermediate approximations to the points of the alternance.

\section{Determination of the approximation of a Chebyshev approximation by the sum of a linear expression and an arctangent function}

To determine the values of the parameters of a Chebyshev approximation by the expression (2), we can use the Remez algorithm [6,7]. If the function $f(x)$ satisfies the condition of the theorem, and $z_{i}$ $(i=\overline{1,4})$ are the points of a Chebyshev alternance, then the parameters $a, b$ and $c$ of a Chebyshev approximation of the function $f(x)$ by the expression (2) with the smallest absolute error on the interval $[\alpha, \beta]$ and with the reproduction of the value of the function at the point $\alpha$ are determined according to the formula

$$
\begin{aligned}
c & =\frac{\frac{f\left(z_{4}\right)-f\left(z_{2}\right)}{z_{4}-z_{2}}-\frac{f\left(z_{3}\right)-f\left(z_{1}\right)}{z_{3}-z_{1}}}{\frac{\arctan \left(d z_{4}\right)-\arctan \left(d z_{2}\right)}{z_{4}-z_{2}}-\frac{\arctan \left(d z_{3}\right)-\arctan \left(d z_{1}\right)}{z_{3}-z_{1}}} ; \\
b & =\frac{f\left(z_{3}\right)-f\left(z_{1}\right)-c\left[\arctan \left(d z_{3}\right)-\arctan \left(d z_{1}\right)\right]}{z_{3}-z_{1}} ; \\
a & =f(\alpha)-b \alpha-c \arctan (d \alpha) .
\end{aligned}
$$

The values of the parameter $d$ are determined as the solution of the equation (12). Taking into account the strictly monotonic nature of the dependence of the left side of the equation (12) on $d$, its solution can be determined by means of Newton's method

$$
d_{i+1}=d_{i}-\frac{G\left(d_{i}\right)-W}{G^{\prime}\left(d_{i}\right)}, \quad i=0,1,2, \ldots
$$

where

$$
\begin{gathered}
d_{0}=\sqrt{\frac{1-\sqrt{k W}}{\sqrt{k W} \zeta_{2}^{2}-\zeta_{1}^{2}}}, \\
k=\frac{\left(z_{2}-z_{1}\right)\left(z_{4}+z_{2}\right)}{\left(z_{3}-z_{2}\right)\left(z_{3}+z_{1}\right)}, \quad \zeta_{1}=\frac{z_{3}+z_{1}}{2}, \quad \zeta_{2}=\frac{z_{4}+z_{2}}{2},
\end{gathered}
$$

the value of $W$ is determined according to $(4)$ and $G(d)$ is determined according to (13).

The choice of the initial value $d_{0}$ by the formula (22) is sufficiently close to the solution of the equation (12). This value is obtained on the basis of the estimation (14) of the value $G(d)$ of the left side of the equation (12).

When using a program that implements the iterative process (21), the convergence of two or three significant digits in the determination of the parameter $d$ was achieved in three-four iterations. 


\section{Approximation by the sum of a linear expression and an arctangent function of the characteristic of electric steel magnetization}

The model (1) corresponds to the approximation by the expression

$$
B(x)=b x+c \arctan (d x), \quad x \geqslant 0, \quad d>0
$$

with respect to the unknown parameters $b, c$ and $d$. A Chebyshev approximation by the expression (23) is an approximation by the sum of a linear expression and an arctangent (2) under the condition of ensuring the equality to zero of the value of the actual function at the point $x=0$. In accordance with the theorem establishing the existence of a Chebyshev approximation by the expression (2), the sufficient condition for the existence of the Chebyshev approximation by the expression (23) is holding the inequalities

$$
0<W<W_{0},
$$

where values $W$ and $W_{0}$ are determined according to the formulae (4) and (5), in which $\alpha=0$ and $f(\alpha)=0$. In the case of satisfaction of the condition (24), the values of the parameters $b$ and $c$ are determined according to the formulae (18) and (19), and the values of the parameter $d$ can be calculated by the Newton's method (21).

We will approximate the characteristic of magnetization of steel of the grade TS3408 [13]. A Chebyshev approximation of the magnetization characteristic of this steel by the expression (23)

$$
B(H)=-4.266574449 \cdot 10^{-3} H+1.273686869 \arctan (0.2213663062 H)
$$

reproduces the magnetic induction of steel in the range of change of the magnetic field strength from 0 to $63 \mathrm{~A} / \mathrm{m}$ with the absolute error of $0.059 \mathrm{~T}$. The detailed results of the reproduction of the magnetization characteristic of the $0.30 \mathrm{~mm}$ thickness steel TS3408 for $B_{\max }=1.7 \mathrm{~T}$ are presented in Table 1 .

Table 1. The results of the reproduction of the magnetization characteristic of the steel TS3408.

\begin{tabular}{|c|c|c|c|}
\hline$H, \mathrm{~A} / \mathrm{m}$ & $B, \mathrm{~T}$ & $\begin{array}{c}B \text { calculated } \\
\text { by Eq. }(25), \mathrm{T}\end{array}$ & Error, T \\
\hline 0 & 0 & 0 & 0.0 \\
\hline 0.375 & 0.1 & 0.10388993 & -0.00389 \\
\hline 0.875 & 0.2 & 0.23995651 & -0.03996 \\
\hline 1.25 & 0.3 & 0.33850278 & -0.0385 \\
\hline 1.625 & 0.4 & 0.43288096 & -0.03288 \\
\hline 2.125 & 0.5 & 0.5509625 & -0.05096 \\
\hline 2.625 & 0.6 & 0.6592645 & -0.05926 \\
\hline 3.0 & 0.7 & 0.73386459 & -0.03386 \\
\hline 3.5 & 0.8 & 0.82464813 & -0.02465 \\
\hline 4.0 & 0.9 & 0.9060084 & -0.006008 \\
\hline 4.563 & 1.0 & 0.98727923 & 0.01272 \\
\hline 5.125 & 1.1 & 1.0586385 & 0.04136 \\
\hline 5.875 & 1.2 & 1.1407351 & 0.05926 \\
\hline 7.063 & 1.3 & 1.2458148 & 0.05419 \\
\hline 8.938 & 1.4 & 1.3665205 & 0.03348 \\
\hline 12.375 & 1.5 & 1.5020978 & -0.002098 \\
\hline 23.625 & 1.6 & 1.6592645 & -0.05926 \\
\hline 63.0 & 1.7 & 1.6407351 & 0.05926 \\
\hline
\end{tabular}


A Chebyshev approximation of the magnetization characteristic of the $0.30 \mathrm{~mm}$ thickness steel of the grade TS3408 for $B_{\max }=1.7, \mathrm{~T}[13]$ by the expression (23)

$$
B(H)=-0.05102738 H+2.15018866 \arctan (0.1161164476 H)
$$

reproduces the magnetic induction of steel in the range of change of the magnetic field strength from 0 to $21 \mathrm{~A} / \mathrm{m}$ with the absolute error $0.031 \mathrm{~T}$.

A Chebyshev approximation of the magnetization characteristic of the $0.35 \mathrm{~mm}$ thickness steel of the grade TS3406 for $B_{\max }=1.7 \mathrm{~T}$ [13] by the expression (23)

$$
B(H)=0.0010982434 H+0.99087245 \arctan (0.7093643948 H)
$$

reproduces the magnetic induction of steel in the range of change of the magnetic field strength from 0 to $190 \mathrm{~A} / \mathrm{m}$ with the absolute error $0.058 \mathrm{~T}$, and the magnetic induction of the same steel for $B_{\max }=1.5 \mathrm{~T}$ in the range of change of the magnetic field strength from 0 to $41 \mathrm{~A} / \mathrm{m}$

$$
B(H)=0.0046206764992 H+0.873985573 \arctan (0.70239702427 H)
$$

is reproduced with the absolute error $0.032 \mathrm{~T}$.

The program module for determination of the parameters of a Chebyshev approximation by the sum of a linear expression and an arctangent (23) is included into the software package "RADAN" [14].

\section{Conclusions}

A sufficient condition for the existence of a Chebyshev approximation by the sum of a linear expression and an arctangent function (3) with the smallest absolute error and with the reproduction of the value of the function at the leftmost point is satisfaction of the inequality (3). The sufficient condition (3) of the existence of a Chebyshev approximation by the expression (2) with the smallest absolute error on the interval $[\alpha, \beta]$ and with the reproduction of the value of the function at the point $\alpha$ is satisfied, in particular, for the continuously differentiable functions $f(x)$ if the function and its two derivatives are strictly monotone over $[\alpha, \beta]$. In this case, the rate of change of the values of the second derivative should not exceed the rate of change of the linear function.

In the case this condition holds, the parameters of a Chebyshev approximation by the sum of a linear expression and an arctangent function (2) are determined by means of the formulae (18)-(20). The values of the parameter $d$ are determined as the solution of the transcendent equation (12), using the Newton's method (21). The initial approximation of parameter $d$ can be determined according to the formula (22).

The Chebyshev approximation of the steel magnetization characteristic by the sum of a linear expression and an arctangent function of three parameters (23) reproduces the magnetic induction of the TS3408 grade electrotechnical steel of the $0.30 \mathrm{~mm}$ thickness for $B_{\max }=1.7 \mathrm{~T}$ in the range of change of the magnetic field strength from 0 to $63 \mathrm{~A} / \mathrm{m}$ with the absolute error of $0.059 \mathrm{~T}$.

[1] Besarab O. B., Tugay Yu. I. Modelling of ferroresonant process in voltage transformer by direct method. Proceedings of the Institute of Electrodynamics NASU. 30, 87-90 (2011), (in Ukranian).

[2] Tugay Yu. I., Besarab O. B. Model of electomagnetic voltage transformer for study of ferroresonance processes. Scientific proceedings of VNTU. 4, 1-5 (2014), (in Ukranian).

[3] Kadomskaya K. P., Laptev O. I. Antirezonansnyie transformatory napryazheniya. Effektivnost primeneniya. Novosti elektrotehniki. 6 (42), 2-5 (2006), (in Russian).

[4] Malyar W.S., Dobushovska I. A. Aproksymatsiia kharakterystyk namahnichuvannia elektrotekhnichnykh stalei splainamy druhoho poriadku. Visnyk Natsionalnoho universytetu "Lvivska politekhnika". Elektroenerhetychni ta elektromekhanichni systemy. 671, 67-71 (2010), (in Ukranian). 
[5] Pan'kiv V.I., Tankevych E. M., Lutchyn M. M. Approximation of magnetization curve of current transformers. Pratsi Instytutu elektrodynamiky Natsionalnoi akademii nauk Ukrainy. 37, 82-90 (2014), (in Ukranian).

[6] Malachivskii P. S., Moncibovych B. R., Pizyur Ya. V., Khapko O. B. Nablyzhennia kharakterystyky namahnichuvannia stali sumoiu liniinoho vyrazu i funktsii arktanhensu. V nauk.-tekhn. konf. "Obchysliuvalni metody i systemy peretvorennia informatsii”. 30-34 (2018), (in Ukranian).

[7] Popov B. A., Tesler G. S. Priblizhenie funktsiy dlya tehnicheskih prilozheniy. Nauk. dumka, Kiev (1989), (in Russian).

[8] Malachivskii P. S., Skopetskii V. V. Continuous and Smooth Minimax Spline Approximation. Nauk. dumka, Kiev (2013), (in Ukranian).

[9] Popov B. A., Malachivskii P. S. Nailuchshie chebyishevskie ppiblizheniya summoy mnogochlena i nelineynyh funktsiy. Prepr. PhMI AN USSR. 85, 79 (1984), (in Russian).

[10] Malachivskii P.S. Chebyshev approximation by the sum of a polynomial and a function with one nonlinear parameter. Fiz.-Mat. Model. Inform. Tekhnol. 1, 134-145 (2005), (in Ukranian).

[11] Skopetskii V.V., Malachivskii P. S. Chebyshev approximation of functions by the sum of a polynomial and an expression with a nonlinear parameter and endpoint interpolation. Cybernetics and Systems Analysis. 45 (1), 58-68 (2009).

[12] Korn G. A. and Korn T. M. Mathematical Handbook for Scientists and Engineers. McGraw-Hill Book Company (1968).

[13] Molotilov B. V., Mironov L. V., Petrenko A.H. Kholodnokatanyye elektrotekhnicheskiye stali: Sprav. izd. Metallurgiya, Moscow (1989), (in Russian).

[14] Malachivskii P.S., Moncibovych B. R. Algoritmy i programmnoye obespecheniye dlya ravnomernoy approksimatsii eksperimentalnykh dannykh. Electronic Modeling. 33 (5), 97-106 (2011), (in Russian).

\title{
Чебишовське наближення характеристики намагнічування сталі сумою лінійного виразу й функції арктангенсу
}

\author{
Малачівський П. ${ }^{1,2}$, Пізюр Я. ${ }^{3}$ \\ ${ }^{1}$ Центр математичного моделювання ІППММ ім. Я. С. Підстригача НАН Украӥни, \\ вул. Дж. Дудаєва, 15, Львів, 79005, Україна \\ ${ }^{2}$ Українсъка академія друкарства, \\ вул. Під Голоском, 19, Львів, 79020, Україна \\ ${ }^{3}$ Національний університет "Львівсъка політехніка", \\ вул. С. Бандери, 12, Лъвів, 79013, Україна
}

Досліджено властивості чебишовського наближення сумою лінійного виразу й функції арктангенсу. Встановлено умову, за якої чебишовське наближення сумою лінійного виразу й функції арктангенсу з найменшою абсолютною похибкою і відтворенням значення функції у крайній лівій точці існує і єдине. Запропоновано й обгрунтовано метод визначення параметрів такого наближення. Подано результати чебишовської апроксимації характеристики намагнічування електротехнічної сталі сумою лінійного виразу й функції арктангенсу.

Ключові слова: чебишовсъке (рівномірне) наближення з умовою, точки чебишовсъкого альтернансу, характеристика намагнічування сталі.

2000 MSC: 41A50, 41A52

УдК: 519.65

Mathematical Modeling and Computing, Vol. 6, No. 1, pp. 77-84 (2019) 